proceso que nada de extraño tiene se hubiese iniciado ya en Andalucía y de aquí fuese llevado al norte de Africa por los expulsados españoles.

Creemos, con lo que queda expuesto, haber resuelto el problema de la etimología de chaval y sus homónimos. Si así no fuera, nos consideraremos satisfechos si en algo hemos contribuído a su elucidación.

Joș́ VÁzQUEz RuIz.

Granada, 1955 .

\title{
UN DATO PARA LA BIOGRAFIA DE QUEVEDO
}

En el transcurso de nuestras investigaciones sistemáticas en los fondos documentales de la Cancillería de los virreyes de Cataluña, custodiados en el Archivo de la Corona de Aragón, de Barcelona, hemos hallado un dato de interés para perfilar un extremo de la biografía de don Francisco de Quevedo y Villegas. Nuestro propósito, en estas líneas, se limita a publicar el documento de referencia, que contradice una afirmación comúnmente admitida sobre el viaje de Quevedo a través de Cataluña en el verano de r6r7.

Desde el primer biógrafo del gran satírico, Pablo Antonio de Tarsia, viene repitiéndose, y así lo hace Astrana Marín, de quien tomamos la cita, la versión de que Quevedo cruzó el territorio catalán en . 1617 , acompañado por una escolta de caballos que le facilitó el entonces virrey del principado, duque de Alburquerque. Quevedo había salido de Nápoles, enviado a España por el duque de Osuna, el $3 I$ de mayo. He aquí el párrafo en cuestión:

Prosiguiendo su viaje, fué avisado (Quevedo) por correo, despachado a toda diligencia desde Marsella, con carta del capitán Vinciguerra, de 4 de julio de aquel año, en que le decia que tres dias después de haber salido de aquella ciudad le habian dado noticia muy cierta que habian partido de Niza seis caballeros, con su retrato y señas. para matarle, juzgando que desembarcaria en aquel puerto para ir 
por ticrra. Otro tal aviso escribió este capitán al duque de Alburquuer que, entonces gobernador y capitán general del principado de Cataluña, el cual, llegando don Francisco a Barcelona, porque no le succdiese algún desinán, le convoyó con una tropa de caballos hasta Fraga de Aragón, sin que en tantos sobresaltos de peligros y asechanzas le vicsen anilanarse ${ }^{1}$.

El documento que aportamos demuestra que, por lo menos en Cataluña, no se temieron sobresaltos ni peligros de ninguna clase. Quevedo no fué acompañado por una tropa de caballos desde Barcelona a Fraga, sino, solamente, por un comisario real con un portero y una mula. Conocemos, incluso, la duración del viaje entre ambas poblaciones: unos cinco días. Queveclo salió de Barcelona el i2 de julio y llegaría a Iiraga el i7 ó el $\mathrm{r} 8$, puesto que el comisario real acompañante, Juan Loscos, estuvo diez días de viaje, entre la ida a Fraga y el regreso a Barcelona ${ }^{2}$.

Con fecha 29 de diciembre de $I 6 I 7^{3}$, el virrey de Cataluna, duque de Alburquerque ", ordenó al regente de la tesorería real del principado, Cristóbal Gallart y de Traginer, que pagara al comisario real, Juan Loscos, la cantidad de doscientos setenta y siete sueldos-casi catorce libras ba rcelonesas"por los diez días que con un portero y una mula viajó desde la presente ciudad de Barcelona hasta la frontera de Aragón, acompañando a don Francisco de Cavedo, que iba a la corte de S. M. enviado por el duque de Osuna, virrey de Nápoles" 5 . Como ya hemos indicado, interpretamos que los diez días se refieren a la ida $y$ regreso.

\section{JUAN Regr.í.}

1 Astrana Marín, I,uis, Francisco de Quevedo y Iillegas. Obras completas. Obras en verso. Madrid, 1943, pág. 759 .

2 Apéndice documental.

3 En el documento consta 1618 , pero hay que restar un año, porque continuaba empleándose el año de la Natividad.

- Francisco Fernández de la Cueva, después embajador en Roma y presidente del Consejo de Aragón.

- Apéndice documental. 


\section{Apéndice documental.}

ACA. Reg. 5216, fol. $209 \mathrm{v}-210$.

$1617-29-X I I-B a r c e l o n a$.

El virrey de Cataluña, duque de Alburquerque, ordena el pago de determinadas cantidades, entre ellas, 277 sueldos al comisario Juan Loscos por el viaje que hizo hasta la frontera de Aragón acompañando a don Francisco de Quevedo.

Noble y amat de la Real Magestat don Cristofol Gallart y de Traginer, regent la real tresoreria, etc. Nos vos manam que de qualsevol diners que son o de proxim seran en poder vostre per raho de vostre carrech doneu y pagueu a Joan Loscos, conissari real, les quantitats devall escrites: Priner, es a saber, doscents y setanta y set sous per deu dies que ab un porter y nula vaga en la anada que ha feta desde la present ciutat de Barcelona fins a la ratlla de Arago acompanyant a don Francisco de Cavedo, que anava a la cort de Sa Magestat enviat per lo duch de Ossuna, virrey de Napols, que partí a dotze de juliol proxim passat. E mes trescents noranta y un sous que ab una mula y sens porter ha vagat en altre anada que per ordre $y$ ab patent nostra ha fet fins a la ratlla de Arago acompanyant a don Angel de Litala, cavalleris de Sa Magestat en lo regne de Cerdenya, qui anave a Madrid ab vint y un cavalls del servei de Sa Magestat; partí desde ciutat a divuit de octubre proppassat. Les quals quantitats juntes prenen suma de siscents sexanta y quatre sous moneda barcelonesa, com apar per los memorials que son estats presentats, adverats per Miquel Camarassa, notari y lochtinent de scriva de racio, y en la paga y solucio que de dits siscents sexanta quatre sous li fareu cobrareu apocha de rebuda y lo present originalment. En virtud del qual diem y manam al illustre mestre racional de la Casa y Cort de Sa Magestat y a son loclitinent y a altre qualsevol etc. (sic). Data en Barcelona a XXVIIII de dezembre MDCXVIII" ${ }^{2}$.

1 Vid. nota 3. 